\title{
DESCRIÇÃO ANATÔMICA DO XILEMA SECUNDÁRIO DE TABERNAEMONTANA CATHARINENSIS A. DC. (APOCYNACEAE) ${ }^{1}$
}

\section{MAILA ARTICO ${ }^{2}$ TALITA BALDIN ${ }^{3}$ LUCIANO DENARDI $^{4}$ SIDINEI RODRIGUES DOS SANTOS 5}

\section{RESUMO}

A anatomia da madeira de Tabernaemontana catharinensis A. DC. (Apocynaceae) é descrita pela primeira vez, com base em material proveniente do Rio Grande do Sul. Foram observados: vasos predominantemente solitários, em porosidade difusa; pontoações intervasculares ornamentadas; parênquima axial extremamente raro ou ausente; tecido radial heterocelular, com células perfuradas; e fibras septadas, com abundantes cristais. Palavras-chave: Anatomia da madeira, Tabernaemontana catharinensis, Peschiera, Apocynaceae.

\section{ABSTRACT}

[Wood anatomy of Tabernaemontana catharinensis A. DC. (Apocynacae)].

The wood anatomy of Tabernaemontana catharinensis A. DC. (Apocynaceae) is described for the first time, based on materials from Rio Grande do Sul state, Brazil. The anatomical structure shows: vessels mostly solitary, in diffuse-porous; vestured intervessel pits; axial parenchyma extremely rare or absent; heterocellular rays, with perforated cells; and septate fibres, with abundant crystals.

Key Words: Wood anatomy, Tabernaemontana catharinensis, Peschiera, Apocynaceae.

\section{INTRODUÇÃO}

A família Apocynaceae inclui aproximadamente 400 gêneros e 3.700 espécies de ervas, subarbustos, árvores e lianas, geralmente latescentes, distribuídas predominantemente em regiões tropicais e subtropicais, mas também com representantes em zonas temperadas (Judd et al., 2009). No Brasil ocorrem cerca de 95

1 Recebido para publicação em 03/10/2010 e aceito para publicação em 30/10/2010.

2 Acadêmica do Curso de Engenharia Florestal do Centro de Educação Superior Norte do Rio Grande do Sul, CESNORS/UFSM, Frederico Westphalen. maylaartico@hotmail.com

3 Acadêmica do Curso de Engenharia Florestal do Centro de Educação Superior Norte do Rio Grande do Sul, CESNORS/UFSM, Frederico Westphalen. taba_m@hotmail.com

${ }^{4}$ Engenheiro Florestal, Doutor, Professor Adjunto do Departamento de Engenharia Florestal, Universidade Federal de Santa Maria/CESNORS, CEP 98400-000, Frederico Westphalen (RS). lucianodenardi@yahoo.com.br

5 Biólogo, bolsista (CNPq - Brasil), doutorando do Programa de Pós-Graduação em Engenharia Florestal, Departamento de Ciências Florestais, Universidade Federal de Santa Maria.sthurt.bio@gmail.com gêneros e 850 espécies, destacando-se, por seu interesse madeireiro ou ornamental, os gêneros Aspidosperma, Allamanda, Asclepias e Tabernaemontana (Souza \& Lorenzi, 2008).

Este último gênero, de especial interesse no presente estudo, reúne cerca de 230 espécies (Judd et al., 2009) em regiões tropicais do Hemisfério Sul, salientando-se para a flora brasileira: Tabernaemontana divaricata (L.) R. Br. ex Roem. \& Schult., T. hilariana Müll. Arg., T. solanifolia A. DC. e T. salzmannii A. DC. (Lorenzi, 2009).

Cabe assinalar que as espécies de Tabernaemontana, geralmente de pequeno porte (3-11 m), carecem de importância devido à baixa resistência da madeira. Lorenzi (2002; 2009) e Lorenzi et al. (2003) indicam-nas, mesmo assim, para caixotaria, tabuados, caibros, lenha e carvão.

De acordo com Lorenzi (2009), Tabernaemontana catharinensis A. DC., conhecida vulgarmente por leiteira, jasmim-catavento e sapirangui, apresenta rica sinonímia botânica (Peschiera catharinensis (A. DC.) Miers, Tabernaemontana australis Müll. Arg., 
Tabernaemontana affinis Müll. Arg., Tabernaemontana hilariana Müll. Arg. e Tabernaemontana acuminata Müll. Arg). Trata-se de planta latescente, com altura de 3-8 m e tronco irregular, revestido por casca grossa, suberosa. As folhas são simples, opostas, e os frutos carnosos e deiscentes.

A distribuição natural de Tabernaemontana catharinensis inclui Argentina, Bolívia, Paraguai, Uruguai e Brasil, de São Paulo ao Rio Grande do Sul (Ezcurra et al., 1992; Leeuwenberg, 1994). Única representante do gênero em solo gaúcho (Sobral et al., 2006), ocorre tanto na floresta do Alto Uruguai (Floresta Estacional Decidual) como na MataAtlântica (Floresta Ombrófila Densa). Em estudo florístico recente, Marchiori \& Alves (2010) citam a ocorrência de T. catharinensis nos "Campos de Areia" ou "Areais" do oeste do Estado.

Para a família Apocynaceae, Record \& Hess (1949) referem os seguintes aspectos anatômicos da madeira: poros predominantemente pequenos, exclusivamente solitários ou com numerosos múltiplos; elementos vasculares curtos a moderadamente longos, com placas de perfuração simples; pontoações intervasculares diminutas e ornamentadas; parênquima axial comumente apotraqueal difuso, em faixas estreitas, ou ausente em gêneros com fibras septadas; raios heterocelulares, tipicamente com 3-5 células de largura e numerosas fileiras de células eretas nas margens; fibras com pontoações simples ou areoladas, septadas ou não; e tubos laticíferos presentes, em raios de vários gêneros.

Com relação à anatomia da madeira de $T$. catharinensis A. DC., as escassas referências devem-se à Gimenez (2004), que trabalhou com exemplares da Isla del Cerrito, província del Chaco (Argentina), e incluem: anéis de crescimento distintos; porosidade difusa, não uniforme; vasos extremamente numerosos $\left(200 / \mathrm{mm}^{2}\right)$ e pequenos $(36 \mu \mathrm{m})$; elementos vasculares de comprimento médio $(524 \mu \mathrm{m})$, com placas de perfuração simples e apêndices em uma ou ambas as extremidades; traqueóides vasicêntricos; fibrotraqueóides, fibras gelatinosas e fibras libriformes septadas, com $979 \mu \mathrm{m}$ de comprimento; parênquima axial paratraqueal escasso; e raios heterogêneos, com células perfuradas.

O presente estudo teve por objetivo a descrição e análise da estrutura anatômica da madeira de Tabernaemontana catharinensis A. DC., com base em material procedente do Rio Grande do Sul.

\section{MATERIAIS E MÉTODOS}

O material em estudo foi coletado no município de Iraí (RS), às margens do Rio Uruguai, em área pertencente à Universidade Federal de Santa Maria (UFSM). O material foi extraído de um indivíduo com aproximadamente $8 \mathrm{~m}$ de altura e $15 \mathrm{~cm}$ de diâmetro à altura do peito (DAP). As exsicatas, bem como a amostra de madeira (torete), foram anexadas no Herbário e Xiloteca do Departamento de Engenharia Florestal (HDEF) da Universidade Federal de Santa Maria (Campus de Frederico Westphalen), sob o número 295.

Da amostra de madeira, foram confeccionados 3 corpos-de-prova, orientados para obtenção dos cortes nos planos anatômicos transversal, longitudinal radial e longitudinal tangencial. O preparo de lâminas histológicas seguiu a técnica padrão: após fervura em água, os corposde-prova foram seccionados em micrótomo de deslize, coloridos com safranina e azul-de-astra, desidratados em série alcoólica crescente e diafanizados com xilol. Em seguida, foram montadas lâminas permanentes, usando-se "Entellan" como meio de montagem.

Para a dissociação do tecido lenhoso, utilizou-se o método Ácido Nítrico-Acético (Barrichelo et al., 1983); a solução macerante, contendo 5 partes de ácido acético para 1 de ácido nítrico, foi posteriormente diluída em água destilada, na proporção 2:1. A maceração foi conduzida em banho-maria, sob ebulição, durante 50 minutos. 
Concluída a maceração, as células foram reunidas em papel filtro, sobre funil, e tingidas com safranina $1 \%$, por 10 minutos. A desidratação foi realizada pela adição de álcool comum $\left(90^{\circ}\right) \mathrm{e}$, posteriormente, álcool absoluto, em intervalos de aproximadamente 2 minutos. Utilizou-se xilol para a diafanização e "Entellan" na montagem das lâminas.

A descrição anatômica foi realizada com base no IAWA Committee (1989) e IBAMA (1992). A determinação da fração dos diferentes tecidos foi obtida em contador de laboratório, segundo a metodologia proposta por Marchiori (1980). Todas as medições e contagens foram feitas em fotomicroscópio LEICA DM 1000, com ocular graduada, no Laboratório de Anatomia da Madeira da UFSM/ CESNORS. As fotografias da madeira foram obtidas com o uso de microscópio Olympus CX40, no Laboratório de Anatomia da Madeira da Universidade Federal do Paraná (UFPR).

No texto descritivo, os valores referentes a determinadas características anatômicas, apresentam-se da seguinte forma: $\mathrm{x} \pm \mathrm{s}$ (valor mínimo-valor máximo), onde: $\mathrm{x}=$ média; $\mathrm{s}=$ desvio padrão

\section{DESCRIÇÃO MICROSCÓPICA}

Aspectos gerais: lenho composto essencialmente por fibras $(64 \%)$, seguido de vasos $(27 \%)$ e raios $(9 \%)$. Anéis de crescimento fracamente demarcados, individualizados por fibras mais lignificadas e radialmente estreitas ao final do lenho tardio (Figura 1A,B).

Vasos: em porosidade difusa, não uniforme, com frequência de $108 \pm 11,8(82-121) / \mathrm{mm}^{2}$. Poros de seção arredondada a ligeiramente poligonal (Figura 1A,B), com $34 \pm 8,1$ (20-50) $\mu \mathrm{m}$ de diâmetro e predominantemente solitários $(65 \%)$ ou em múltiplos radiais $(35 \%)$ de $2-4$ unidades (Figura 1A). Elementos vasculares de $570 \pm 91,1$ (400-750) $\mu \mathrm{m}$ de comprimento, com apêndices em uma ou ambas as extremidades e placas de perfuração simples, oblíquas (Figura $1 \mathrm{C}, \mathrm{F})$; espessamentos helicoidais, estriações, tiloses e depósitos, ausentes. Pontoações intervasculares alternas, ornamentadas e arredondadas (3-6 $\mu \mathrm{m}$ de diâmetro), com abertura inclusa, lenticular, horizontal ou oblíqua. Pontoações raio-vasculares semelhantes às intervasculares, principalmente no contato com células procumbentes e quadradas, ou então, aparentemente simples, se adjacentes a células eretas.

Parênquima axial: extremamente raro ou ausente.

Raios: heterocelulares, com frequência de $10 \pm 2,3$ (7-14) raios/mm, compostos por células procumbentes, quadradas e eretas (Figura 1C). Raios unisseriados (47\%), compostos predominantemente por células eretas, ou então por células quadradas e eretas (Figura $1 \mathrm{~F}$ ); medem $406 \pm 134,6(220-650) \mu \mathrm{m}$ de altura, com $7 \pm$ 2,50 (4-11) células, e $17 \pm 4,96$ (10-28) $\mu \mathrm{m}$ de largura. Raios multisseriados, em sua maioria trisseriados $(32 \%)$, menos comumente bisseriados $(16 \%)$ e tetrasseriados $(5 \%)$. Reúnem células procumbentes, ao centro, normalmente com uma fileira de células quadradas e 2-4 fileiras de células eretas nas extremidades, ou então apenas com células procumbentes e numerosas fileiras de células eretas nas margens (Figura 1F); medem $480 \pm 168,83$ (220-1010) $\mu \mathrm{m}$ de altura, com $14 \pm 4,53$ (8-25) células, e 42 $\pm 6,37$ (30-60) $\mu \mathrm{m}$ de largura. Raios fusionados, raros. Células perfuradas, com uma a duas perfurações simples, pouco freqüentes (Figura 1D).

Fibras: libriformes septadas (Figura 1E,F), com pontoações simples ou areoladas, neste caso com abertura lenticular, oblíqua, exclusa, presente apenas nas faces radiais da parede. São muito curtas a curtas, $1090 \pm 165,8$ (760-1390) $\mu \mathrm{m}$, com paredes delgadas a espessas, $4 \pm 1,33$ (1-6) $\mu \mathrm{m}$ e desprovidas de espessamentos helicoidais. Fibras gelatinosas em estreitas faixas tangenciais ou então dispersas no lenho; pouco abundantes. Traqueóides vasculares ou vasicêntricos, ausentes no material examinado.

Outros caracteres: cristais romboédricos, geralmente formando "massas granulares" no 


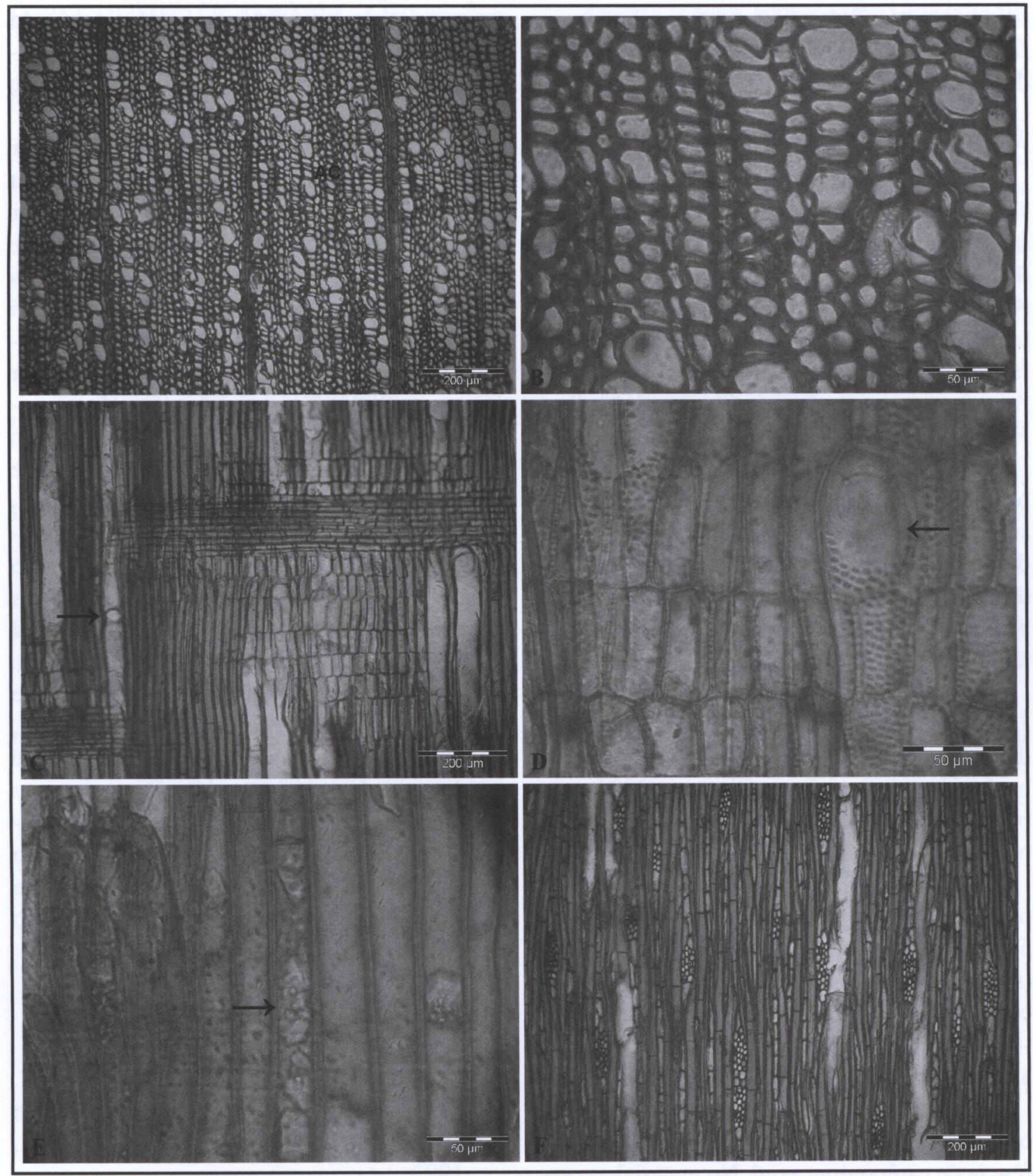

FIGURA 1 - Fotomicrografias do lenho de Tabernaemontana catharinensis. A - Seção transversal, exibindo porosidade difusa, vasos solitários e limite tênue de anel de crescimento (AC). B - Mesma seção, com destaque para as fibras radialmente estreitas ao final do lenho tardio. C - Plano radial, destacando raios heterocelulares e placas de perfuração simples (seta). D - Plano radial, mostrando célula perfurada de raio (seta). E - Fibras septadas, com cristais diminutos, abundantes (seta), em plano radial. F - Raios unisseriados, constituídos por células eretas, e raios multisseriados com até 4 células de largura, em plano tangencial. 
interior das fibras, freqüentes (Figura 1E). Estrutura estratificada, canais intercelulares, canais celulares, células oleíferas e mucilaginosas, floema incluso, máculas medulares e cistos glandulares, ausentes.

\section{ANÁLISE DA ESTRUTURA ANATÔMICA}

As características anatômicas do lenho de Tabernaemontana catharinensis A. DC. concordam, em linhas gerais, com o descrito por Record \& Hess (1949) para a família Apocynaceae. A presença de poros predominantemente solitários é também referida para numerosas espécies da família, como em Aspidosperma quebrachoblanco Schltdl. e Rauvolfia sellowii Müll. Arg., ambas nativas do Rio Grande do Sul (Marchiori et al., 2009; Marchiori et al., 2010). Da mesma forma, a observação de elementos vasculares com placas de perfuração simples, de raios heterocelulares, de fibras septadas, bem como a ausência de parênquima axial, são aspectos amplamente citados na literatura para as Apocináceas.

A presença de células perfuradas de raio, com 1 ou 2 perfurações simples, embora não referida por Record \& Hess (1949) para a família, já havia sido mencionada por Gimenez (2004) para o lenho de $T$. catharinensis, com base em exemplares da Argentina.

A constatação, no presente estudo, de poros pequenos $(34 \mu \mathrm{m})$, de elementos vasculares de $570 \mu \mathrm{m}$ de comprimento, de fibras libriformes (septadas) com aproximadamente $1000 \mu \mathrm{m}$ de comprimento, e de raios heterocelulares com 1 -4 células de largura, ajusta-se, perfeitamente, à descrição realizada por Gimenez (2004).

Algumas características, no entanto, merecem exame mais criterioso, caso da virtual ausência de parênquima axial. No material em estudo, em verdade, encontrou-se apenas uma série de parênquima axial, composta de 7 células com paredes relativamente espessas, após exaustiva procura. Em contraponto, Gimenez (2004) refere a presença de parênquima axial paratraqueal escasso. Cabe inferir, que o fre- qüente contato entre vasos e raios unisseriados (formados por cerca de 7 células eretas, de paredes relativamente estreitas), principalmente quando observado nos planos longitudinais, talvez tenha induzido o autor a um suposto erro de interpretação.

Com relação à frequiência de poros, o valor presentemente encontrado $\left(108 / \mathrm{mm}^{2}\right)$ representa cerca da metade do referido $\left(200 / \mathrm{mm}^{2}\right)$ por Gimenez (2004). Convém lembrar, todavia, que este caráter é sabidamente afetado por fatores ecológicos, principalmente no que diz respeito à disponibilidade hídrica; no entanto, causa estranheza, na comparação com o descrito por Gimenez (2004), o acentuado aumento no número de poros $/ \mathrm{mm}^{2}$ (108 para 200), tendo-se em vista que o diâmetro dos mesmos manteve-se praticamente idêntico, em ambos os estudos.

Cabe agregar, por fim, a presença abundante de numerosos cristais diminutos, formando uma espécie de "massa granular" no lúmen das fibras. Tal aspecto, embora pouco referido na literatura, justifica-se, pelo menos em parte, pela "maior longevidade" das fibras septadas, que podem exercer a função de parênquima axial, principalmente em madeiras desprovidas deste tecido, caso da espécie descrita. Resta destacar a presença de pontoações intervasculares ornamentadas. Embora tenha passado despercebido por Gimenez (2004), tal aspecto revela-se de grande valor diagnóstico, posto que o gênero Tabernaemontana inclui numerosas espécies.

\section{BIBLIOGRAFIA}

BARRICHELO, L.E.G.; FOELKEL, C.E.B. Processo nítrico-acético para maceração de madeira. Silvicultura, n. 28: p. 732-733, 1983.

EZCURRA, C.; ENDRESS, M.E.; LEEUWENBER, A. Apocynaceae. Flora del Paraguay, v. 17, n.1, p. 1-121, 1992.

GIMENEZ, A.M.; Anatomía de leño y corteza de Tabernaemontana catharinensis A. DC (Apocynaceae). Quebracho. Revista de 
Ciências Forestales, Santiago del Estero, n. 11, p. 22-32, 2004.

IAWA COMMITTEE. IAWA list of microscopic features for hardwood identificacion. IAWA Bulletin, v. 10, n. 3, p. 218-359, 1989.

IBAMA. Instituto Brasileiro do Meio Ambiente e dos Recursos Naturais Renováveis. Diretoria de Incentivo à pesquisa e divulgação. Laboratório de Produtos Florestais. Normas e procedimentos em estudos de Anatomia da madeira: I Angiospermae II - Gimnospermae. Brasília, Série Técnica, 15, p. 7-13, 1992.

JUDD, W.S.; CAMPBELL, C.S.; KELLOGG, E.A.; STEVENS, P.F.; DONOGHU, M.J. Sistemática vegetal: Um enfoque filogenético. Porto Alegre: Artmed, 2009. p. 471-475.

LEEUWENBERG, A. A revision of Tabernaemontana. The New World species. Royal Botanic Gardens, Kew, v. 2, p. 213-450, 1994.

LORENZI, H. Árvores Brasileiras: Manual de Identificação e Cultivo de Plantas Arbóreas Nativas do Brasil. Nova Odessa: Instituto Plantarum, 2002. v. 4. p. 45.

LORENZI, H. Árvores Brasileiras: Manual de identificação e cultivo de plantas arbóreas nativas do Brasil. Nova Odessa: Instituto Plantarum, 2009. v. 3. p. 39-41.

LORENZI, H.; SOUZA, H.M.; TORRES, M.A.V; et al. Árvores Exóticas no Brasil: Madeireiras, ornamentais e aromáticas. Nova Odessa: Instituto Plantarum, 2003. p. 92.
MARCHIORI, J.N.C.; Estudo anatômico do xilema secundário de algumas espécies dos gêneros Acacia e Mimosa, nativas no Rio Grande do Sul. 1980. 186 f. Dissertação (Mestrado em Engenharia Florestal) - Universidade Federal do Paraná, Curitiba, 1980.

MARCHIORI, J.N.C; MUÑIZ, G.I.B; SANTOS, S.R. Madeiras do Rio Grande do Sul: 1 - Descrição microscópica de 33 espécies nativas. Santa Maria: [s.n.], 2009. p. 24.

MARCHIORI, J.N.C; MUÑIZ, G.I.B; SANTOS, S.R. Madeiras do Rio Grande do Sul: 2 - Descrição microscópica de 35 espécies nativas. Santa Maria: Anaterra, 2010. p. 66.

MARCHIORI, J.N.C.; ALVES, F.S. Campos de areia e silvicultura no oeste do Rio Grande do Sul: Enfoque Fitogeográfico. Balduinia, Santa Maria, n. 23, p. 01-20, 2010.

RECORD, S.J.; HESS R.W. Timbers of de New World. New Haven: Yale University Press, 1949. $640 \mathrm{p}$.

SOBRAL, M.; JARENKOW, J.A.; BRACK, P.; IRGANG, B.; LAROCCA, J.; RODRIGUES, R.S. ; Flora arbórea e arborescente do Rio Grande do Sul, Brasil. São Carlos: RiMa: Novo Ambiente, 2006. 350p.

SOUZA, V.C.; LORENZI, H. Botânica sistemática: Guia ilustrado para identificação das famílias de Fanerógamas nativas e exóticas no Brasil, baseado em APG II. Nova Odessa: Instituto Plantarum, 2008. p. 546-558. 